Available online at https://jurnal.stmikroyal.ac.id/index.php/jurdimas

\title{
PELATIHAN PENYUSUNAN SOAL HIGHER ORDER THINKING SKILLS (HOTS) DI SMK PEMBANGUNAN DENPASAR
}

\author{
Ni Putu Meina Ayuningsih*¹, Ni Made Dwijayani ${ }^{1}$, Ketut Gus Oka Ciptahadi ${ }^{1}$ \\ ${ }^{1}$ Sistem Informasi, ITB STIKOM Bali \\ email:*meinageg@gmail.com
}

\begin{abstract}
The low HOTS (Higher Order Thinking Skills) students based on the results of PISA 2015 in mathematics shows the characteristics of mathematics learning are still familiar with Lower Order Thinking Skills (LOTS) questions. Based on this, HOTS math problems need to be developed at the Vocational high school education level. The difficulty of the teacher in applying HOTS questions is due to the lack of information obtained by the teacher and the lack of sharing activities to compile HOTS questions. The purpose of this community service activity is to provide training for vocational mathematics teachers in making HOTS questions. This community service activity is in the form of training for Mathematics Teachers of Denpasar Development Vocational School and involving all teachers of mathematics subjects. The partner in this dedication activity named I Made Surya Mega Widiastha, S.Pd is one of the mathematics teachers at the Denpasar Development Vocational School. The implementation of community service activities is carried out through three stages, namely planning, implementation, and reflection. Based on the results of the questionnaire given to the partners and to the school, the results of the service have been able to run well.
\end{abstract}

Keywords: Dedication, Mathematics, Training, Hots

\begin{abstract}
Abstrak: Rendahnya HOTS (Higher Order Thinking Skills) siswa berdasarkan hasil PISA 2015 dalam matematika menunjukkan karakteristik pembelajaran matematika masih terbiasa dengan soal-soal Lower Order Thinking Skills (LOTS). Berdasarkan hal tersebut, perlu dikembangkan soal matematika HOTS di jenjang pendidikan sekolah menengah Kejuruan. Kesulitan guru dalam menerapkan soal-soal HOTS dikarenakan kurangnya informasi yang diperoleh guru serta minimnya kegiatan sharing untuk menyusun soal HOTS. Tujuan kegiatan pengabdian masyarakat ini untuk memberikan pelatihan bagi guru matematika SMK dalam membuat soal-soal HOTS. Kegiatan pengabdian masyarakat ini berupa pelatihan kepada guru matematika SMK Pembangunan Denpasar dan melibatkan semua guru mata pelajaran matematika. Mitra pada kegiatan pengabdian ini bernama I Made Surya Mega Widiastha, S.Pd merupakan salah satu guru matematika di SMK Pembangunan Denpasar. Pelaksanaan kegiatan pengabdian masyarakat ini dilakukan melalui tiga tahapan, yaitu perencanaan, implementasi, dan refleksi. Berdasarkan hasil kuisioner yang diberikan kepada pihak mitra maupun ke pihak sekolah diperoleh hasil pengabdian sudah dapat berjalan dengan baik.
\end{abstract}

Kata kunci: Pengabdian, Matematika, Pelatihan, Hots 
Available online at https://jurnal.stmikroyal.ac.id/index.php/jurdimas

\section{PENDAHULUAN}

Berdasarkan hasil tes dan evaluasi tiga tahunan PISA (Programme for International Student Assessment) tahun 2015 dengan judul "PISA 2015 Result in Focus" Indonesia masih memiliki performa yang jauh dari harapan. Indonesia masih menempati peringkat 10 dari bawah dari 72 negara yang mengikuti. Oleh sebab itu, diperlukan latihan mengerjakan soal-soal nonrutin seperti HOTS dalam meningkatkan kemampuan berpikir siswa. Para guru dan tenaga pendidik harus memahami taksonomi berpikir dan pemecahan masalah secara kreatif oleh Krulik-Rudnick.

Selain itu, pemahaman terhadap berbagai taksonomi dan pemeringkatan pemahaman siswa guna menguasai level kognitif dalam pemecahan masalah menjadi salah satu upaya meningkatkan mutu pembelajaran. Dalam membantu siswa mengembangkan kemampuan tersebut, maka diperlukan latihan HOTS. Dengan demikian, dalam proses belajar mengajar di kelas seperti ketika ulangan harian, UTS atau UKK, guru dapat memberikan soal-soal atau latihan yang memuat HOTS.

Namun yang menjadi masalah bagi guru adalah kurang tersedianya soal-soal non-rutin seperti HOTS, sehingga untuk meningkatkan kemampuan berpikir siswa masih kurang maksimal. Salah satu cara untuk mengatasi permasalahan di atas adalah dengan memberi sejumlah latihan soal HOTS dalam pemecahanmasalah dalam hal ini yaitu soal-soal matematika.

Laporan hasil Trends in International Mathematics and Science Study (TIMSS) tahun 2011 menunjukkan bahwa rata-rata skor prestasi sains peserta didik Indonesia sebesar 406 (peringkat 40 dari 42 negara) (Salirawati, 2012). Demikian juga rata-rata skor prestasi matematika peserta didik Indonesia pada tahun yang sama sebesar 389 (peringkat 41 dari 45 negara) (Rosnawati, 2012). Hampir sebagian besar soal-soal sains dalam TIMSS yang mengungkap aspek aplikasi (applying) dan penalaran (reasoning) tidak dapat dijawab oleh sebagian besar pe- serta didik Indonesia. Soal-soal tersebut hanya dapat dijawab jika peserta didik terbiasa diajarkan untuk menggunakan logika dan penalarannya dan selalu mengaitkan materi pelajaran dengan aplikasinya dalam kehidupan. Berdasarkan hasil TIMSS itulah, saat ini guru diharapkan mampu menyusun soal yang Higher Order Thinking Skill (HOTS), yaitu soal-soal yang mampu mengungkap kognitif tingkat tinggi.

Namun, untuk menyusun soal HOTS masih banyak guru yang belum memahami dan menguasainya, baik ciri-ciri soal HOTS maupun bagaimana mengubah soal biasa menjadi soal HOTS. Bahkan soal Uji Kompetensi Guru (UKG) yang barubaru ini dilaksanakan mengarah pada soal yang termasuk dalam kategori soal HOTS. Guru matematika SMA penting untuk dilatih mengembangkan soal yang termasuk HOTS. Hal ini sejalan dengan anjuran yang tercantum dalam PP Nomor 19/2005 Pasal 19 Ayat 1 yang menyatakan bahwa proses pembelajaran pada satuan pendidikan diselenggarakan secara inspiratif, interaktif, menyenangkan, menantang, dan memotivasi peserta didik untuk berpartisipasi aktif.

Kegiatan pengabdian ini bertujuan untuk memberikan pemahaman tentang ciriciri dan cara pengembangan soal HOTS yang berkualitas baik, memberikan pengalaman langsung dalam mengubah soal biasa menjadi soal HOTS dan dalam pengembangan soal HOTS bagi guru-guru matematika di SMK Pembangunan Denpasar. Melalui kegiatan pengabdian ini diharapkan mampu menumbuhkan kesadaran guru-guru matematika SMK tentang pentingnya mengembangkan kemampuan mengevaluasi peserta didik dengan selalu mengikuti perkembangan yang terjadi di dunia pendidikan, sehingga dapat meningkatkan kompetensi pedagogiknya.

\section{METODE PENDEKATAN}

Melalui kegiatan pengabdian masyarakat pelatihan dan penyuluhan ini akan ditawarkan solusi bagi permasalahan- 
Available online at https://jurnal.stmikroyal.ac.id/index.php/jurdimas

permasalahan yang telah dirumuskan di atas. Pendekatan yang ditawarkan bagi realisasi program pengabdian masyarakat pelatihan dan penyuluhan ini adalah dengan memberdayakan guru-guru matematika di SMK Pembangunan Denpasar dengan tahapan kegiatan sebagai berikut:

1. Tahap Perencanaan Program atau Kegiatan

2. Tahap Pelaksanaan (Implementasi) Program atau Kegiatan

3. Tahap Refleksi

\section{Lokasi Pengabdian}

SMK Pembangunan Denpasar merupakan salah satu SMK swasta yang terletak di kecamatan Denpasar Utara tepatnya di jalan Sari Gading No. 2, Dangin Puri Kaja.

\section{Rencana Kegiatan}

Pelaksanaan kegiatan pengabdian masyarakat ini dilakukan melalui tiga tahapan, yaitu perencanaan, implementasi, dan refleksi yang diuraikan di bawah ini.

\section{Kegiatan Perencanaan}

Kegiatan ini dilakukan dengan penyusunan program, sosialisasi program, dan penyusunan materi pelatihan. Pada kegiatan ini yang dilibatkan adalah guru matematika SMK Pembangunan Denpasar. Tujuan dari kegiatan ini adalah mengenalkan program pengabdian yang akan dilaksanakan. Selain itu, pada tahap perencanaan ini juga dilaksanakan penyusunan materi yang disesuaikan dengan kebutuhan guru terkait soal HOTS.

\section{Tahap Implementasi}

Pelaksanaan program pengabdian dilaksanakan selama kurang lebih tujuh bulan yang jadwalnya disesuaikan dengan kegiatan guru matematika SMK Pembangunan Denpasar. Beberapa hal yang dilakukan adalah memberikan informasi terkait kriteria soal HOTS sehingga guru mampu menyusun soal HOTS yang bertujuan untuk mengukur kemampuan siswa dan meningkatkan kemampuan matematis siswa. Selain itu, setelah guru memahami kriteria soal HOTS, maka dilakukan pelatihan dan pendampingan dalam penyusunan soal HOTS. Hal ini bertujuan agar guru dapat mengalami langsung bagaimana cara menyusun soal HOTS.

\section{Tahap Refleksi}

Kegiatan yang dilakukan adalah dengan menganalisis respon peserta terhadap pelatihan yang telah dilakukan. Tujuan dari kegiatan ini adalah sebagai masukan kepada pelaksana pengabdian yang dapat digunakan untuk kegiatan pengabdian berikutnya.

\section{Luaran Kegiatan}

Luaran kegiatan yang akan dihasilkan dari pelatihan pengabdian masyarakat ini antara lain:

1. Respons positif dari peserta pelatihan

Respons peserta terhadap pelatihan yang diberikan akan diukur melalui observasi selama pelatihan berlangsung dan menggunakan kuisioner yang berisi kesan, saran, kritik serta usulan peserta pelatihan terhadap program pengabdian masyarakat mandiri ini.

2. Guru matematika mampu menyusun soal HOTS dalam $1 \mathrm{KD}$.

3. Laporan Hasil Kegiatan Pengabdian Masyarakat Mandiri

\section{PEMBAHASAN}

Pelaksanaan kegiatan pengabdian masyarakat ini dilakukan melalui tiga tahapan, yaitu perencanaan, implementasi, dan refleksi. Dari seluruh kegiatan yang telah dilakukan oleh mitra dan pelatih dapat disimpulkan bahwa kegiatan berjalan dengan baik. Mitra dan peserta sangat antusias dalam kegiatan pengabdian yang telah dilaksanakan. Adapun rincian kegiatan pengabdian adalah seperti dibawah ini: 
Available online at https://jurnal.stmikroyal.ac.id/index.php/jurdimas

\section{Hasil Kegiatan Perencanaan}

Kegiatan perencanaan ini dilaksanakan selama 6 minggu yaitu meliputi penyusunan program, sosialisasi program, dan penyusunan materi pelatihan. Kegiatan awal yang kami lakukan adalah meminta ijin dengan Kepala Sekolah untuk melaksanakan kegiatan Pengabdian di SMK Pembangunan Denpasar pada tanggal 18 Agustus 2019. Kemudian dilaksanakan sosialisasi pada tanggal 9 September 2019 Pukul 09.0012.00 WITA. Dilakukan dengan Kepala Sekolah SMK Pembangunan Denpasar untuk menyampaikan informasi-informasi mengenai latar belakang, target, sasaran dan tujuan kegiatan pelaksanaan Pengabdian Masyarakat ini. Pada kegiatan ini yang dilibatkan adalah guru matematika SMK Pembangunan Denpasar yang akan berkolaborasi dengan Penulis dalam penentuan materi yang disesuaikan dengan kebutuhan guru terkait soal HOTS.

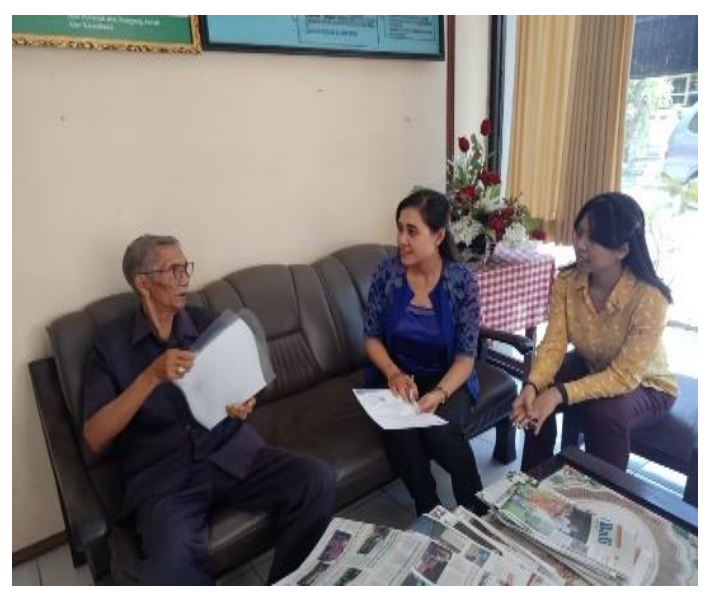

Gambar1. Sosialisasi Materi Pengabdian

\section{Hasil Implementasi}

Pelaksanaan diawali dengan mem-
berikan informasi terkait mengenai pengertian sooal HOTS, kriteria soal HOTS, bagaimana cara membuat kisi-kisi Soal HOTS, dan kartu soal HOTS yang dilaksanakan pada mulai tanggal 16 September 2019 sampai 30 September 2019. Hal ini akan berdampak sehingga guru mampu me- nyusun soal HOTS yang bertujuan untuk mengukur kemampuan siswa dan meningkatkan kemampuan matematis siswa.

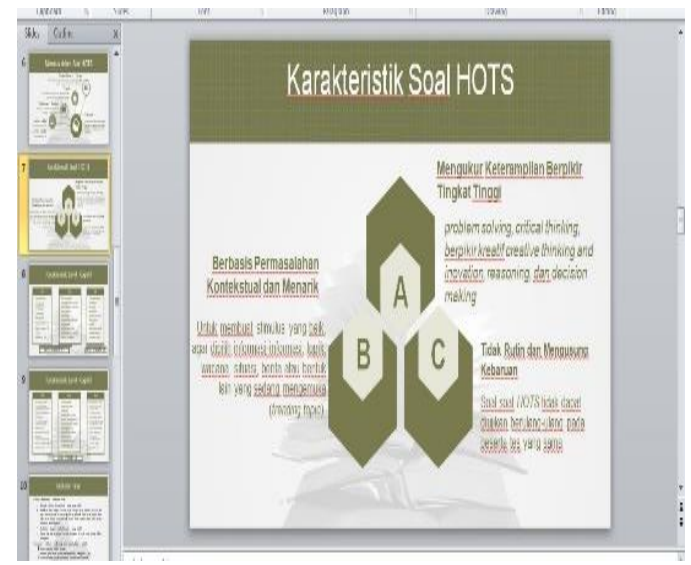

Gambar 2. Kriteria Soal HOTS

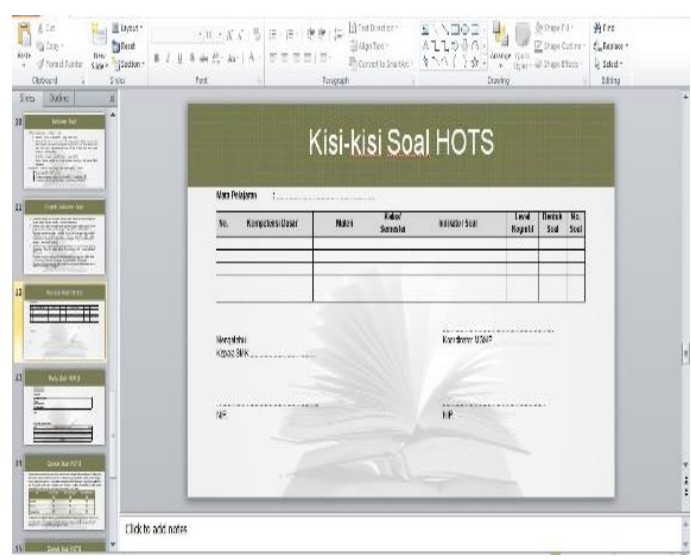

Gambar 3. Kisi kisi soal HOTS

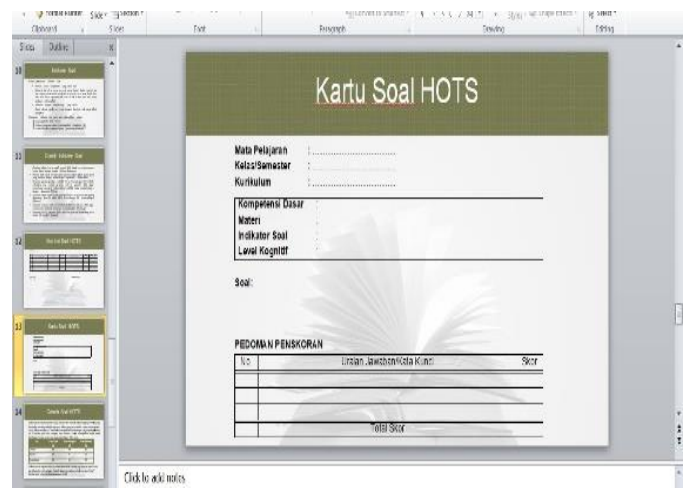

Gambar 4. Kartu Soal HOTS

Kemudian, setelah guru memahami materi soal HOTS, maka dilakukan pelatihan dan pendampingan dalam penyusunan soal 
Available online at https://jurnal.stmikroyal.ac.id/index.php/jurdimas

HOTS mulai tanggal 19 September 2019 sampai 19 November 2019 yang disesuaikan dengan jadwal Mitra di lokasi. Hal ini bertujuan agar guru dapat mengalami langsung bagaimana cara menyusun soal HOTS.

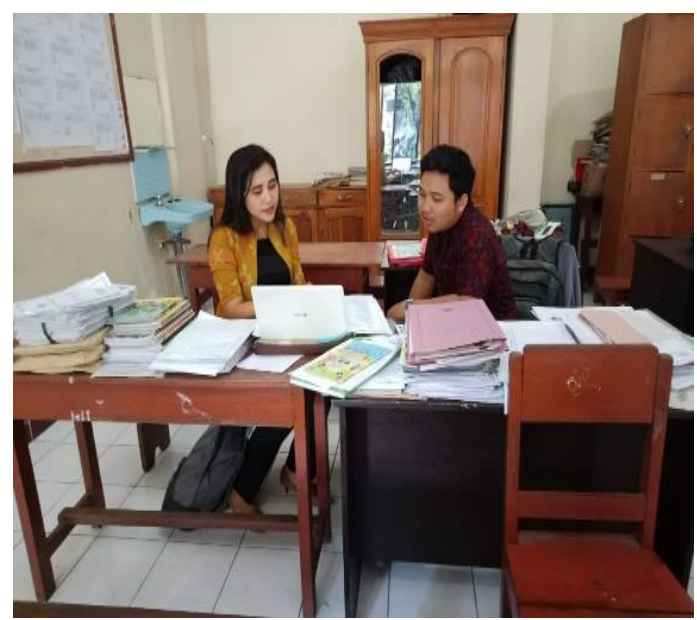

Gambar 5. Penyusunan Soal HOTS

\section{Tahap Refleksi}

Tujuan dari kegiatan ini adalah sebagai masukan kepada pelaksana pengabdian yang dapat digunakan untuk kegiatan pengabdian berikutnya. Kegiatan ini dilakukan pada tanggal Jumat 6 Desember 2019 dengan teknik evaluasi yang diberikan adalah dengan memberikan kuisioner kepada peserta pelatihan.

Kesimpulan dari kuisioner yang telah diberikan adalah dari pihak mitra pengabdian masyarakat yang diwakili Bapak I Made Surya Mega Widiastha, S.Pd memberikan penilaian antara baik sampai memuaskan/baik sekali untuk pelaksanaan penyuluhan/pelatihan dan tim pelaksana serta memberikan komentar bahwa penyuluhan dan pelatihan ini mempunyai kinerja baik, bermanfaat bagi SMK Pembangunan Denpasar, dan berharap kegiatan sejenis bisa dilakukan secara berkesinambungan di masa mendatang.

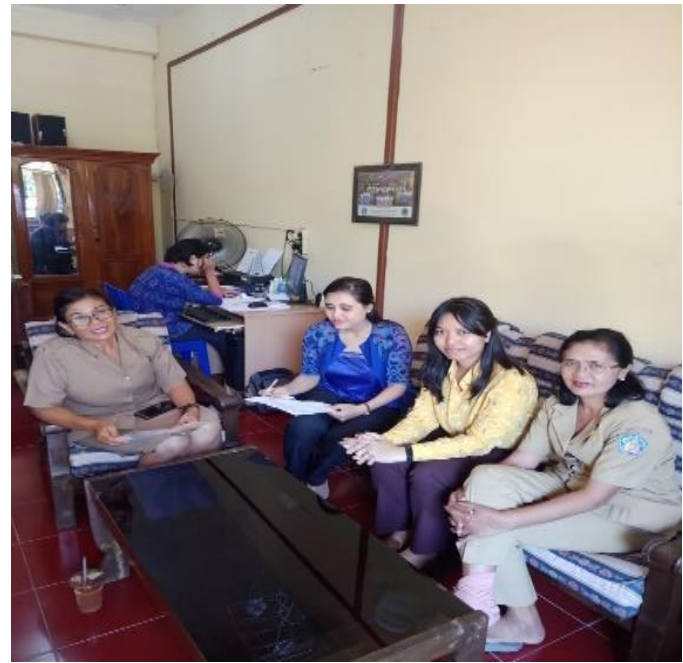

Gambar 6. Evaluasi Kegiatan

\section{SIMPULAN}

Terdapat beberapa kesimpulan yang dapat diambil dari pengabdian masyarakat ini adalah.

1. Pengabdian masyarakat berupa Pelatihan Pengembangan Penyusunan soal Higher Order Thinking Skills (HOTS) di SMK Pembangunan Denpasar sudah berjalan dengan sangat baik. Hal ini dibuktikan dengan hasil kuisioner yang diisi oleh pihak mitra yaitu perwakilan dari pihak sekolah SMK Pembangunan Denpasar dan guru peserta pelatihan.

2. Peserta pelatihan mampu memahami dan meningkatkan keterampilan dalam menyusun soal Higher Order Thinking Skills atau disingkat (HOTS) sehingga dapat mengembangkan kemampuan mengenai pedagogiknya.

\section{DAFTAR PUSTAKA}

Depdiknas. (2005). PP RI No. 19/2005: Standar Nasional Pendidikan. Jakarta: Depdiknas.

Lewy, Zulkardi, \& Aisyah, Nyimas. (2009). Pengembangan Soal Untuk Mengukur Kemampuan Berpikir Tingkat Tinggi Pokok Baha- 
Available online at https://jurnal.stmikroyal.ac.id/index.php/jurdimas

san Barisan dan Deret Bilangan

Di Kelas IX Akselerasi SMP Xaverius Maria Palembang, Jurnal Pendidikan Matematika, 3(2): 1428. https://scholar.google.com/citatio ns.

OECD. (2016). PISA 2015 Result in Focus. (Online), terse- dia:(http://www.oecd.org/pisa), diakses pada tanggal 5 Oktober 2018.

Rosnawati. (2012). "Profil Kemampuan Peserta Didik Indonesia Menurut Benchmark lnternasional (Bidang Matematika)". Makalah Seminar Nasional Hotel Salak Heritage. Bogor. Tanggal 3 Desember 2012. 